\title{
Circuit
}

Musiques contemporaines

\section{Itinéraire à compléter}

\section{Joane Hétu}

Volume 6, numéro 2, 1995

Musique actuelle?

URI : https://id.erudit.org/iderudit/902128ar

DOI : https://doi.org/10.7202/902128ar

Aller au sommaire du numéro

Éditeur(s)

Les Presses de l'Université de Montréal

ISSN

1183-1693 (imprimé)

1488-9692 (numérique)

Découvrir la revue

Citer ce document

Hétu, J. (1995). Itinéraire à compléter. Circuit, 6(2), 9-10.

https://doi.org/10.7202/902128ar

\section{Résumé de l'article}

$\mathrm{Au}$ travers de courtes contributions, parfois à caractère poétique, quelques acteurs de la musique actuelle (Hétu, Palardy Roger, Derome, Gervais, Côté) et des « décideurs " (Swift, du Conseil des arts, et Prévost, de la Société

Radio-Canada) tentent de définir ce qu'on peut entendre aujourd'hui par " musique actuelle », souvent par différence avec la " musique

contemporaine ». Certains auteurs jouent le jeu, d'autres dénoncent l'entreprise ou disent leur malaise devant un exercice considéré comme nominaliste. Tous insistent sur le métissage, le décloisonnement et l'hybridité des styles et des pratiques et font l'éloge de la spontanéité.
Ce document est protégé par la loi sur le droit d'auteur. L'utilisation des services d’Érudit (y compris la reproduction) est assujettie à sa politique d'utilisation que vous pouvez consulter en ligne.

https://apropos.erudit.org/fr/usagers/politique-dutilisation/ 


\section{DÉFINIR LA MUSIQUE ACTUELLE ?}

\section{Itinéraire à compléter \\ Joane Hétu}

- un amalgame

- un décloisonnement des différents genres musicaux

- inclassable

- à l'intersection d'influences et de styles connus

- une musique hybride

- qui tend à abolir la distinction entre interprète/compositeur/improvisateur

- I'actualité

- la cohabitation de différents genres

- une musique à risque

- la virtuosité versus l'imaginaire, la créativité

- irrécupérable

- le savoir-faire, l'audace, la spontanéité

- le réinvestissement des compositeurs en tant qu'interprètes de leur propre musique

- manger les os

- l'ouverture d'esprit

- une manière de composer

- très méconnue du public

- le sentiment de ne plus être inclus dans la nature

- pour initiés

- sous le choc

- manger du bruit

- notre malheur, notre bonheur

- un petit feu de braise

- une proposition, non un renoncement

- qu'est ce qu'un beau son?
- un assemblage perméable et réversible

- un banc d'essai

- inclure plutôt qu'exclure

- faut-il avoir peur de la musique actuelle?

- une science de l'âme

- s'investir passionnément

- un magasin de textures, un catalogue de styles

- oui, elle bouscule, se trompe, transforme, sculpte

- ne figure pas à la grille-horaire des radios

- I'art actuel

- jouer avec le feu

- dites-moi ce qu'est la poésie?

- une musique non-académique

- le reflet d'une société en transformation

- le sens du sacré

- une rupture, une réconciliation

- le pouvoir du partage

- être une musicienne engagée

- un acte

- jover avec l'air

- une musique à voir

- un geste personnel

- se libérer de l'argent

- une musique avec peu de moyens financiers

- un milieu dynamique mais dans l'ombre

- clair-obscur

- une pomme-poire 
- les journalistes, connais pas...

- non résistante aux changements

- perturbable

- sans agents de conservation

- un métissage

- par instinct de survie

- un circuit indépendant

- de grands et grandes artistes

- la présence des femmes

- un art brut

- une mosaïque

- une vitrine mal éclairée

- ce n'est pas nouveau, c'est vivant

- une théorie des ensembles

- une pizza aux crevettes el au gingembre

- un calquage de notre époque

- un parti-pris

- pas une question de goût, une question de vie

- un système de valeur

- la débrouillardise

- le zapping sonore

- le corps qui danse

- une musique populaire engagée et intelligente
- de la recherche et du développement

- une mutation

- un son de choix

- ce n'est pas une religion

- une tribu parmi les autres

- le tohu-bohu

- des musiques innovatrices

- le don de soi

- une île bizarre

- sans convention collective

- du respect

- sans domicile fixe

- du déconstructivisme

- des chansons en français

- une union libre

- de manière personnelle

- des artisans

- avec ou sans manipulation

- une improvisation dirigée

- un art en transformation

- un dessin sans dessin

- un jugement de valeur

- j'aime! 